\title{
VARIABLES INFLUENCING SENTENCING SEVERITY: INTERCOURT DIFFERENCES IN CONNECTICUT
}

\author{
MARC G. Gertz \\ School of Criminology \\ The Florida State University \\ Tallahasee, Florida 32306
}

\author{
Albert C. Price \\ Department of Political Science \\ The University of Michigan-Flint \\ Flint, Michigan 48502
}

\begin{abstract}
Studies of criminal-court dispositions have traditionally aggregated courts along political and geographic boundaries. This article suggests that courts should be analyzed individually, even within the same jurisdiction, as a means of increasing the explanatory capacity of the variables involved. Further, it is contended that intercourt differences are a result of organizational influences operating within each court.
\end{abstract}

The literature on courts suggests that judges have enormous latitude in allocating sanctions among convicted offenders. This sentencing discretion allows for substantial variation in the treatment of individuals before the bench. Over time many researchers have attempted to articulate the factors that influence sentencing dispositions in criminal courts. Hogarth (1971), in a study of Toronto magistrates, found that sentencing decisions were influenced by many variables, one of the most important of which was the jurist's penal philosophy (rehabilitation, retribution, deterrence, incapacitation). The composition of the courtroom work group (judge, prosecutor, and defense counsel) was found by Eisenstein and Jacob (1977) to be a major explanatory variable; different work-group combinations produced different sentencing outcomes. Marvin Frankel, a judge, himself described judicial decision making on sanctions as existing within a "sentencing wilderness," an opinion further developed in his sarcastically entitled book Criminal Sentences (Frankel, 1972, 1973). 
For the most part, research on courts has centered on demonstrating the obvious sources of variation in sentencing by comparing outcomes across political jurisdictions. Even Eisenstein and Jacob concentrated most of their effort on comparing the explanatory power of their model in three urban areas in different states. State laws and judicial customs differ, and. therefore, it is not surprising that the model would provide differing results.

This stress on interstate dispositional patterns has masked a potentially important research focus by ignoring the variation in sentencing that exists within the same political jurisdiction; in other words, within intrastate sanctioning practices. Even when studies have been conducted within a particular jurisdiction, the tendency has been to treat the state, region, city, or county as though sentencing practices were uniform across all of the courts within the jurisdiction. An examination of Hagan's (1974) review article on "extralegal attributes" demonstrates the existing narrowness of vision concerning intercourt variation within a state. The article provides a table that lists "salient" independent, dependent, and legal variables that have been controlled in nearly every major study of sentencing done in the United States since 1928. Omitted from all of the studies examined, as well as from Ilagan's review, is any research that examines variation among courts within the same local jurisdiction. What this means is that all courts in huge states, such as Pennsylvania or North Carolina, and all courts in large urban areas, such as Detroit and Philadelphia, are treated as though they were the same.

While some studies have examined intrastate sentencing patterns, they have not controlled for individual courts. Bullock (1961) examined the influence of race upon sentencing decisions in Texas but aggregated the courts according to a rural/urban conceptualization. Scholars recently have begun to address more directly the problem of intercourt sentencing variation; for example, Brereton and Casper (1981) found that some California counties use real sanc- tions and differential sentencing to induce guilty pleas. This means that differing court jurisdictions administering the same state laws tend to produce varying results. However. opportunities for further research in the area of intercourt sentencing variation have not been exploited yet to any substantial degree. The following study examines the variation in criminal dispositions among court jurisdictions in Connecticut.

\section{THE RESEARCH}

This research examines the sentencing of felony defendants who faced charges in five of Connecticut's nine superior-court locations: Hartford, New Haven, Middlesex. Tolland, and Windham. The purpose of this article is to demonstrate the differences found in each of the courts and to show that generalizations across courts must be made very tentatively. If it can be demonstrated that there are major differences in courts operating under the same penal code within one state, then comparing and generalizing about courts in a broader framework may be problematic.

To examine intercourt sentencing variation, data were collected on 401 convicted felony defendants in five of the nine superior-court locations in Connecticut for the period of June 1, 1974, to May 31. 1975. The choice of courts for analysis is significant. New Haven and Hartford together account for over half the felony arrests in the state. Of the four busiest superior courts (Hartford, New Haven, New London, and Fairfield). Hartford and New Haven are the largest and appear, from the available 1974 aggregate data, to be highly dissimilar. Whereas in Hartford more than 74 percent of all dispositions result in convictions, in New Haven over 51 percent of all dispositions terminate without convictions. In Hartford 87 percent of the cases are disposed of in less than six months, in New Haven over half the cases take one year or longer. In the smaller communities (operationalized to mean fewer than one hundred felony dispositions in FY 1974). Tolland and 
Windham seem to be similar, while both differ markedly from Middlesex Superior Court. The final selection, thus, includes a sample of cases from five courts, including rural and city, high-volume and low-volume courts. ${ }^{\prime}$

The predominant method for gathering data included an examination of convicted defendants' files made available by the State of Connecticut's Department of Adult Probation. Individual files consist of a face sheet, the presentence investigation, and the state attorney's information. These files, maintained at various probation offices throughout the state, reveal information ranging from background characteristics of the defendants (e.g., race, sex, occupation, prior criminal record) to the interactions between the defendant and the court (e.g., disposition of sentence, type of lawyer, length of time between arrest and conviction). The uniformity of the reports greatly facilitates the collection of data.

A second method of gathering data involved direct observation of the courts in action. The closed nature of the court system-the attempt to hide actions from outsiders - - presents problems of data analysis on at least three levels. On one level, much of the court's important work takes place apart from public view, so that interested observers see only the end product. A court clerk in Hartford said, "We do more in the back room than we do in the court. That's where all the plea bargaining takes place." - On a second level, the attitude of system officials is that their work, by right, should be secret. The same clerk said one had to ask his permission to sit and take notes in open court. On a third level, there is a legal obstacle. The Connecticut General Assembly has enacted an erasure law that disallows examination of a defendant's record if he or she has been acquitted or nol prossed. Because of these three problem areas, certain seemingly key variables and cases were not collectible. Different pleas and the number and kinds of continuances are kept only in the court clerk's files. As a result of the control the clerk exercises, it is impossible to study the effect, for example, of increasing the number of continuances on the dispositional process (Banfield and Anderson, 1968). Also, the law precludes studying both acquitted and convicted defendants.

\section{ANALYSIS}

In the initial stages, the analysis of sources of intercourt sentencing variation was grounded in the concepts and methodologies suggested in the literature discussed above. A relatively large number of variables were examined to determine the extent to which they influence the severity of disposition in Connecticut's superior courts. The independent variables were reduced through a number of stepwise-regression procedures that deleted variables with little explanatory strength. The list of empirical indicators included standard information. such as offense charged; condition of victim; victim knew offender; premises of offense; age, sex, prior record, employment status, education, race, and mental status of defendant; amount of bond; offender's story; time between arrest and disposition; number of eyewitnesses available. ${ }^{3}$ A severityof-disposition-interval-level scale was the dependent variable in this analysis. ${ }^{4}$ Problems of multicollinearity and autocorrelation were explored, and when two variables had a highly significant relationship, one was deleted.

Initially, the data were aggregated for all five courts, and the explanatory power of the variables that we employed was extremely limited. ${ }^{5}$ When the data were disaggregated, through the use of physical controls for court locations, an interesting set of findings emerged. When analyzed on a court-by-court basis, the explanatory capacity of the variables improved markedly. This indicates that lumping the state's courts together may tend to mask the significance of the relationships between independent and dependent variables. The conclusion here is that the most appropriate method for analyzing variations between courts is to examine each court individually. The reason 
for this conclusion is that statistical control tends to obscure variation by using a mathematical averaging process that shows equal variations in opposite directions as having no influence.

Table 1 , below, summarizes the findings, grouped by court location, of the regression analysis. Each court has a nearly discrete set of factors that influence the severity of disposition in Connecticut's superior courts. The size of the standardized beta-weights and $r^{2}$ 's for each court are impressive. When these results developed, our intuition about intracourt variation received credence, and it was then necessary to develop a reasonable explanation of why it is possible to explain the process of disposition for individual courts, but not for the aggregation at the state level. A more detailed discussion of Table 1 provides some insights into this problem.

Table 1 is complicated, so care is necessary in examining and interpreting the information provided. The first striking features are the $r$ 's. For each of the court locations, there is a relatively important $r^{2}$, ranging from .42 (Windham) to .59 (Middlesex). In the social sciences, numbers of this magnitude do not arise randomly, and it is therefore vital to understand exactly what these results represent. A second interesting facet of Table 1 is that the variables that make up the percentage of variation explained are largely unique to each court. For example, the following variables are important in Windham: undercover agent used, reduced conviction, and time between arrest-disposition. In Hartford the salient variables are amount of bond, charged offense, and convicted at trial. The overall $r$ 's for Hartford and Windham are similar.48 and .42 , respectively-but the variables that produce the $r$ 's are completely different. Similar situations exist in each of the courts, and it is useful at this juncture to briefly describe the most important variables (those that make up the bulk of the $r$ 's) for each court location.

In Hartford the most salient variable is clearly amount of bond, with charged offense and convicted at trial coming in a distant second and third. This differs in New Haven, where the important variable is condition of victim, with number of prior felony convictions second and convicted at trial third. As in New Haven. in Middlesex the strongest predictor is condition of victim, followed by number of prior felony convictions and money or goods taken. A fourth variable, amount of bond (which overlaps with the Hartford Court), adds slightly to the explained variance. The amount of bond is the most important explanatory variable in Tolland. just as it is in Hartford. The remaining factors in Tolland are completely unique: employment and other evidence available fill the second and third slots. Finally, the Windham court represents another unique blend of components; undercover agent used provides the bulk of the explained variance, and reduced conviction and time between arrest-disposition add a small increment to the total $r$.

The courts in Connecticut each manifest a markedly different character in terms of the variables that explain sentencing severity. At this point, it is appropriate to address the topic of exactly how it is possible to explain sentencing variation in individual courts, but not possible in the aggregation of Connecticut superior courts. The answer has two parts: one, methodological and technical and the other. theoretical and conceptual.

First, let us discuss the technical aspects of why the explanatory power of the model increases when courts are physically controlled. When stepwise regression is used. it is possible to establish parameters for the deletion of variables that do not significantly add to the total $r^{2}$ (Nie et al. 1975.) For the purpose of this research, we established the deletion threshold at beta $>.10$ and $r^{2}>$ .01 . This means that any variable that did not exceed both thresholds was deleted from the regression procedure. The ultimate impact of this process was to delete most of the variables, because very few were important to a majority of the courts, and aggregation caused the courts to be treated as a single unit. For example, undercover agents used was a very important variable in 


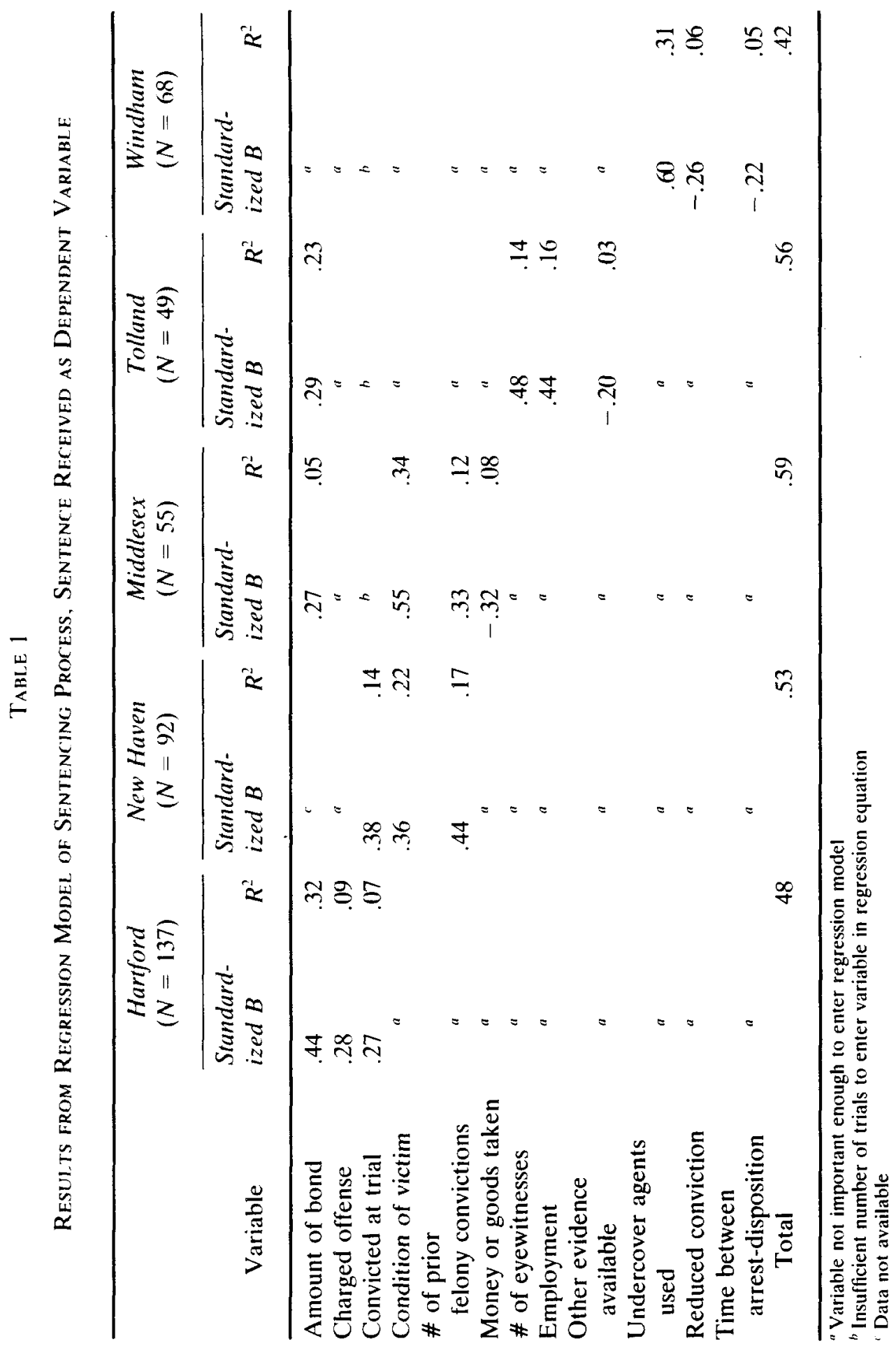


Windham; however, it was not important ( $b$ $>.10$ and $\left.r^{2}>.01\right)$ in the other courts. Aggregation of the courts would eliminate this variable because it did not exceed the deletion threshold for the state of Connecticut as a unit. Most of the salient variables were similarly situated, and the explanatory power of the analysis greatly diminished.

In a theoretical sense, it is easily possible to understand how aggregation can mask a diversity of phenomena. If we speak of the Democratic Party as a unit, we risk combining elements that are very diverse. For example, George Wallace is a Democrat and Edward Kennedy is a Democrat, but their views are dissimilar on a number of issues. Alternatively, Ronald Reagan is a Republican, as is Lowell Weiker; lumping the two together surely reduces the clarity provided by viewing them as individuals. We are not claiming that courts are as uniquely individual as people, but, at least to a degree, it is plausible to assume that courts have significant differences, even within the same state. This important theoretical development is supported by the analysis provided in Table 1 . The courts in Connecticut are indeed diverse; important factors vary from location to location. How much better an understanding of the processes of criminal justice might we have now if the studies reviewed by Hagan had included individual courts as an important control variable?

Another way of looking at Table 1 provides an interesting perspective on the operation of criminal courts. If the independent variables are carefully examined, they seem to break down into three analytical categories: characteristic of the act, of the accused, and of the organizational influences of the criminal-justice system. The characteristics of the act refer to the variables that surround the particular crime being dealt with by the court. In Table 1 characteristics of the act might include offense charged, condition of victim, and money or goods taken. Similarly, the characteristics of the accused refer to such things as number of prior felony convictions and employment. Finally, the characteristics of the organizational influences of the criminal-justice system refer to the components of the process that can be manipulated. or that were expended, by the system to proceed with case. These variables might include amount of bond, convicted at trial. number of eyewitnesses, other evidence available. undercover agents used, reduced conviction, and time between arrestdisposition. ${ }^{\circ}$ If these three categories make sense, then it is obvious that the most explanatory variables in Table 1 relate to the organizational influences of the criminal-justice system. This interpretation suggests that the variables that are most important in understanding severity of disposition in Connecticut courts are organizational. In three of the five courts, the most salient variable is organization related (Hartford, Tolland, and Windham), while the act is most important in the remaining two courts (New Haven and Middlesex). This perspective does not diminish the principal finding of Table 1, because organizational influences vary from court to court. Our interpretation is speculative at this stage. but would certainly fit nicely with the "crimecontrol" model discussed by Packer (1980). From a crime-control perspective, the bureaucratic nature of the criminal-justice system is the dominant force in the processing of criminals in the United States. Our finding that the organizational needs of the system influence the severity of sentences in individual courts fits nicely into a crimecontrol model.

\section{CONCLUSIONS AND IMPLICATIONS}

This paper has attempted to fill a gap that exists in the literature discussing the dispositional processes of criminal courts. Specifically, we examined sentencing severity in five Connecticut superior courts. At first, we were guided by the standard theoretical structure of the discipline, which stresses statewide aggregation of courts. This process produced results that were not important and did not help to explain variation in sentencing. However, when the disposi- 
tional data were disaggregated, through physical control for individual courts, the results were significant. In essence, we found that while the state courts could not be explained as a group, they could be articulated very well on the basis of individual court locations. The conclusion is that the superior courts are sufficiently diverse that it clouds our understanding to speak of them as a single, aggregate unit. Further, we found that the variables that had the most impact in the most settings were related to the organizational needs of the criminaljustice system.

This research suggests two things. First and foremost, we must begin to come to grips with the problem of the aggregation of criminal courts by states or large metropolitan areas. Table 1 demonstrates, at a minimum, that there is sufficient reason to pursue research on sentencing criteria on a court-bycourt basis. This has not been done in the past, and our understanding of court processes has suffered correspondingly. Second, and more tentatively, this research suggests that the disposition of criminal cases may be related to the organizational needs of the criminal-justice system. This line of inquiry should also be pursued on a court-by-court basis, as the organizational needs of the system appear to be location specific.

Finally, this study has important implications for the study of criminal-justice reform and, more specifically, sentencing reform. If courts within the same state are indeed somewhat unique, then doesn't it follow that remedies for disparity in sentencing should also be related to particular courts? This conclusion implies that the type of sentencing reform suggested by Nagel (1983), whereby states alter their criminal codes to adopt the average sentences meted out in the past, is doomed to failure, because the averages are distorted by the aggregation problem we have described. This research demonstrates that one of the most salient features of intrastate sentencing variation is the individual flavor of the particular court organizations themselves. Therefore, we suggest that serious considerations of sentencing reform be premised upon an adequate understanding of the criteria that have influenced sentencing in the past. Until we stop grouping together courts, even within the same political jurisdiction, as though they were the same, an adequate understanding of the courts will be lacking.

\section{NOTES}

'Because of the small number of felony dispositions each year in the light-volume courts, the entire population of cases was used; in Hartford and New Haven. systematic one-in-three samples were collected.

- All interviews were conducted between January 15 . 1975 and October 15. 1975

- A complete examination of our variable list and code book exceeds the space availability of this paper. The coding of the variables used in Table 1 are as follows:

\begin{tabular}{|c|c|}
\hline $\begin{array}{l}\text { Variable Name: } \\
\text { amount of bond }\end{array}$ & $\begin{array}{l}\text { Code: } \\
\text { in dollars }\end{array}$ \\
\hline charged offense & $\begin{array}{l}1=\text { drugs } \\
2=D \text { felony } \\
3=C \text { felony } \\
4=B \text { felony } \\
5=\text { A felony }\end{array}$ \\
\hline convicted at trial & $\begin{array}{l}0=\text { no } \\
1=\text { yes }\end{array}$ \\
\hline condition of victim & $\begin{aligned} 1= & \text { unharmed } \\
2= & \text { force } \\
& \text { threat- } \\
& \text { ened but } \\
& \text { not used } \\
3= & \text { attempted } \\
& \text { assault } \\
4= & \text { assaulted } \\
& \text { (raped. } \\
& \text { beaten, } \\
& \text { etc.) } \\
5= & \text { killed }\end{aligned}$ \\
\hline \# of prior felony convictions & $\begin{array}{l}0=0 \\
1=1 \\
\text { etc. }\end{array}$ \\
\hline money or goods taken & $\begin{array}{l}0=\text { no } \\
1=\text { yes }\end{array}$ \\
\hline \# of eyewitnesses & $\begin{array}{l}0=0 \\
1=1 \\
\text { etc. }\end{array}$ \\
\hline employment & $\begin{aligned} 0= & \text { continually } \\
& \text { employed } \\
1= & \text { not } \\
& \text { continually } \\
& \text { employed }\end{aligned}$ \\
\hline other evidence available & $\begin{aligned} 0= & \text { some } \\
& \text { evidence } \\
& \text { missing } \\
& \text { (e.g.. } \\
& \text { drugs, car. } \\
& \text { etc.) } \\
1= & \text { all relevant } \\
& \text { evidence }\end{aligned}$ \\
\hline
\end{tabular}




$\begin{array}{ll}\text { undercover agents used } & 0=\text { no } \\ & 1=\text { yes } \\ \text { reduced conviction } & 0=\text { yes } \\ \text { time between arrest-disposition } & 1=\text { in months }\end{array}$

Severity of disposition is the dependent variable. It is a measurement of the sentence meted out in court. It consists of eighty categories and was constructed from a number of variables: minimum sentence. maximum sentence, length of probation, and fine.

The key variable was minimum sentence, since most defendants' release dates from Connecticut prisons are based on two-thirds of the minimum. The decision to add probation to a prison sentence necessitated an assumption about the relative impact of prison time versus probation. Each year in prison was treated the same as five years probation.

The dependent variable starts at 0 (straight suspended sentence-no jail time, no probation) and ranges up through 80 (minimum sentence of twentytwo years).

As an example of the coding scheme, 15 on severity of disposition meant a sentence including a one-year minimum in prison; 16 meant a one-year minimum in prison plus one year of probation: 17 meant a one-year minimum in prison plus two years probation: and so on. up to 20, which meant a minimum sentence of two years in prison or one year in prison and five years probation.

For example, a series of relevant variables in a regression equation explained less than 19 percent.

"For example. while number of eye witnesses may be seen by some as a characteristic of the offense. it is also a factor that the judicial process can manipulate. During the plea-bargaining stage. the number of eye witnesses may convince the prosecutor either to forego plea bargaining or pursue it. In this sense, it is a variable the judicial process can use to its advantage in its negotiations with the defendant.

\section{REFERENCES}

Bantield. L.. and Anderson. C. D. (1968). Continuances in the Cook County criminal courts. $U \mathrm{C} / \mathrm{hi} \mathrm{L}$ Rev 35:259-316.

Brereton. D. and Casper, J.. (1981). Does it pay to plead guilty?: Differential sentencing and functioning of criminal courts. Law Soc $R$ 16:45-70).

Bullock. A. (1961). Significance of the racial factor in the length of prison sentences. $J$ Crim Law Criminol Police Sci 52:411-17.

Connecticut General Statules, Section 5-901 revised to January 1. 1975).

Eisenstein. J., and Jacob. H. (1977). Felony iustice. Boston. MA: Little. Brown and Company.

Frankel. M. E. (1972). Lawlessness in sentencing. $U^{\prime}$ $\operatorname{Cin} L \operatorname{Rev}+1: 1-54$.

Frankel. M. E. (1973). Criminal sentences: Law without order. New York: Hill and Wang.

Hagan. J. (1974). Extra-legal attributes and criminal sentencing: An assessment of a sociological viewpoint. Law Soc $R$ 4:357-83.

Hogarth. J. (1971). Sentencing as a human process. Toronto: University of Toronto Press.

Nagel, S. S. (1983). Codifying sentencing experience. In Criminal corrections: Ideals and realities. ed. J. Doig. 195-208. Lexington. MA: Lexington Books.

Nie, N. H.: Hull, C. H.; Jenkins, J. G., Steinbrenner. K.; and Bent. D. H. (1975). Statistical package for the social sciences. 2nd ed. New York: McGrawHill Book Co.

Packer, H. (1980)). Two models of the criminal process. In Criminal justice: Law and politics. 3rd ed.. ed. G. F. Cole. 17-34. North Scituate, MA: Duxbury Press. 


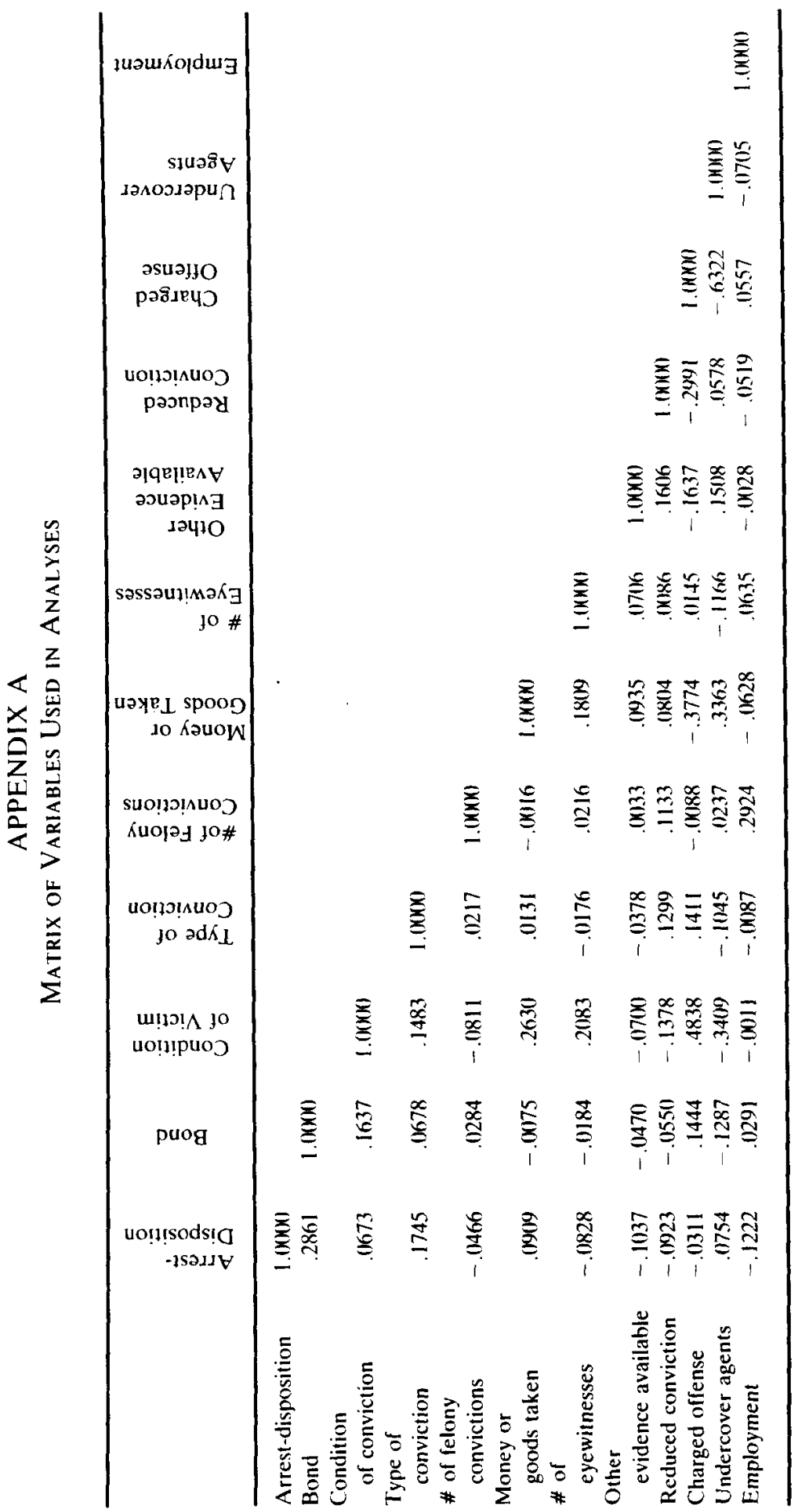

